\title{
REWAS 2013: Enabling Materials Resource Sustainability Plenary Session
}

\author{
GABRIELLE GAUSTAD ${ }^{1,2}$ \\ 1.-Golisano Institute for Sustainability, Rochester Institute of Technology, Rochester 14623, NY, \\ USA. 2.—e-mail: gabrielle.gaustad@rit.edu
}

Current concerns about ever increasing material consumption and waste combined with the TMS 2013 Annual Meeting provided a perfect atmosphere to relaunch REWAS, a symposium organized to highlight sustainability challenges and opportunities within the material science field. Our successfully realized goal was to bring new awareness to the technical community through targeted talks that highlight a broader, more systems-level perspective to current sustainability-related work. The REWAS 2013 Organizing Committee comprised Christina Meskers, Anne Kvithyld, Gabrielle Gaustad, Randolph Kirchain, Gregory Krumdick, Diana Lados, Brajendra Mishra, Markus Reuter, Mark Schlesinger, and Cong Wang. The plenary session was the first opportunity to provide this perspective and included a diverse, international group of distinguished speakers from several different industries. Despite the breadth of experience and current application areas, each shared the same outlook-material scientists are a key enabling force to achieving sustainability in our world.

The session kicked off with the presentation of the Light Metals Recycling Technology Best Paper award to Randolph Kirchain of the Massachusetts Institute of Technology (MIT), as shown in Fig. 1. Kirchain acknowledged his co-authors Tracey Brommer of PA Consulting, Britt Elin Gihleengen of Scandpower, and Elsa Olivetti of MIT and then gave a talk highlighting some of the key results of their work in secondary aluminum production. This work leverages mathematical modeling tools to help make smarter blending decisions, enabling use of more scrap material to make the process both more environmentally friendly and less expensive.

The first plenary speaker (Fig. 2) was Todd DiNoia, the technical director for Habitat research and development at Saint-Gobain's High Performance Materials Research and Development Center. DiNoia highlighted some of Saint Gobain's innovative products for improving indoor air quality such as their gypsum board that captures formaldehyde.

Bill Bader, the second plenary speaker, is the current CEO of the International Electronics Manufacturing Initiative (iNEMI), a diverse, international group that enables collaboration between large groups of corporations and academics. Beyond these linkages, the group also provides technology roadmaps and drives collaborative $R \& D$ on key manufacturing gaps for the electronics industry including challenges in sustainability. Bader highlighted some of the future areas for targeted research and development such as maximizing resource efficiency, barriers to reaching recycling potentials, and integration and advancement of lifecycle assessment tools.

The chief energy technologies at Lawrence Livermore National Laboratory (LLNL), Julio Friedman, shared LLNL's focus on the "enabling technologies that will boost sustainability efforts in key areas" such as water systems, advanced manufacturing, and computationally aided design. Friedman highlighted work being done in capacitive deionization and nanofiber filtration of water as well as microfluidics work developing beads for carbon capture. He detailed how LLNL aims to balance "conflicting commercial signals and metrics" in order to achieve sustainability.

William Bonkoski, a vice president with General Electric Water and Process Technologies (GE), shared how GE is innovating to address current global challenges of availability and quality of energy, water, and material resources. Bonkoski detailed some of GE's newest products for water filtration and purification such as a new membrane bioreactor that uses 30\% less energy than other systems while maintaining a high water quality. For water systems, there are tradeoffs between the degree of reuse possible, complexity of the system, and cost. He highlighted how research is moving from typical chemical- and equipment-based treatment 


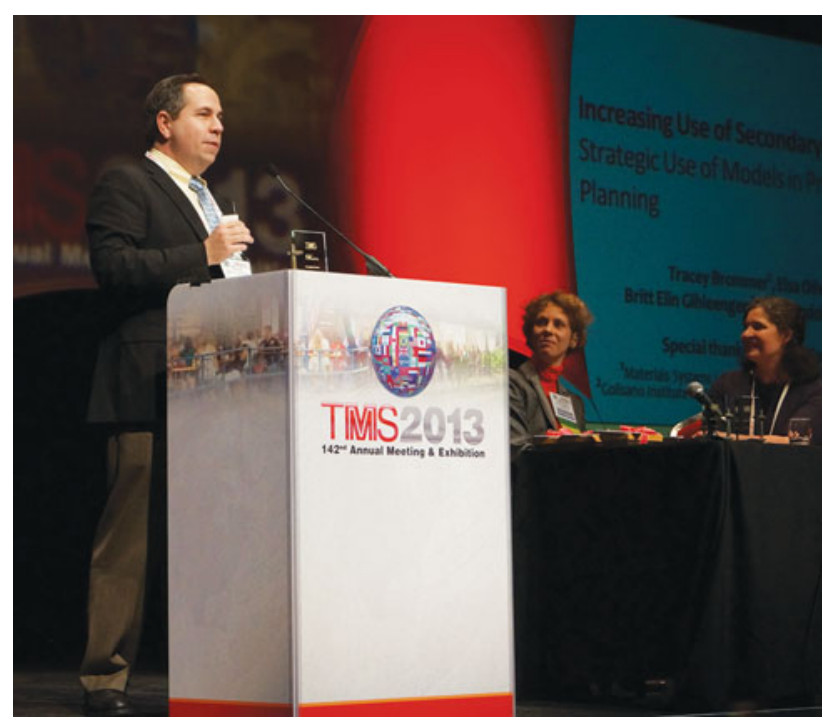

Fig. 1. Randolph Kirchain delivering the Light Metals Recycling Technology Best Paper presentation; REWAS co-organizers Christina Meskers (left) and Anne Kvithyld (right) are in the background.

to efficient separation and better understanding of the water-energy nexus.

An expert consultant with McKinsey, Helga Vanthournout is currently working to quantify and identify opportunities for achieving a circular economy, that is, an industrial system that reincorporates waste and byproducts. She stressed that "for the materials industry to enable a shift toward sustainability, stakeholders need to look at the system-level as well as have a clear understanding of industry influence." She highlighted case studies of market innovators that responded to changing resource markets with increased efficiency, changes in supply, and large-scale system redesign.

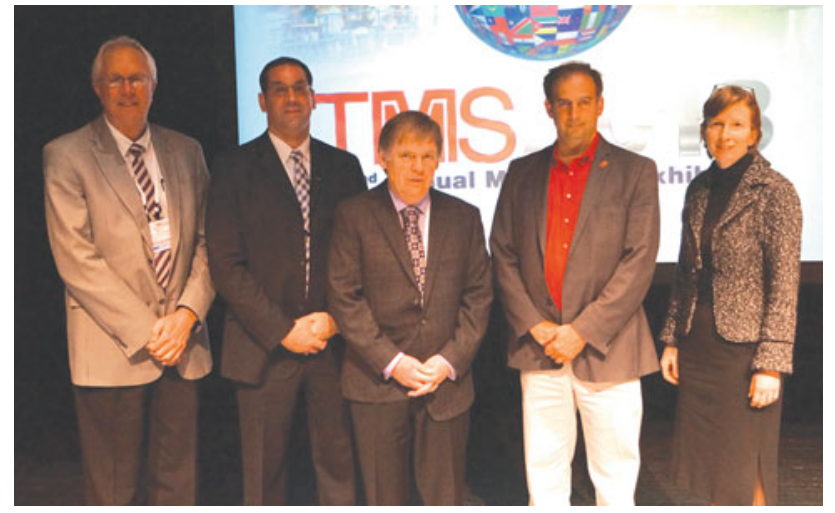

Fig. 2. REWAS Plenary Speakers, left-right William Bonkoski (GE Water and Process Technologies), Todd DiNoia (Saint-Gobain High Performance Materials), Bill Bader (International Electronics Manufacturing Initiative), S. Julio Friedmann (Lawrence Livermore National Laboratory), and Helga Vanthournout (McKinsey).

Vanthournout also gave examples of how value in use can encourage recycling and how new business models (e.g., leasing) were enabling sustainability through market change.

REWAS also provided an avenue to highlight the sustainability-related sessions sponsored by each of the divisions across TMS and brought these groups together for enhanced visibility and networking. The plenary talks set the stage for presentations on a wide range of topics aimed at realizing, enabling, and understanding sustainability. Speakers integrated technical research areas with a wide range of broader methodologies including life-cycle assessment, systems modeling, and industrial ecology. This type of life-cycle thinking and systems perspective was shown to be a key enabler in solving multidisciplinary challenges currently faced by material scientists. 